\title{
Development of a rapid mitochondrial DNA extraction method for species identification in milk and milk products
}

\author{
J. Liao, ${ }^{*}$ Y. F. Liu, ${ }^{* 1}$ L. Yang, ${ }^{*}$ F. P. Li, ${ }^{*}$ and A. M. Sheppard† \\ ${ }^{*}$ College of Food Engineering and Nutritional Science, Shaanxi Normal University, Xi'an, 710062, China \\ †Liggins Institute, The University of Auckland, Auckland 1023, New Zealand
}

\begin{abstract}
Isolation of mitochondrial DNA (mtDNA) from milk offers an effective way to monitor aspects of quality control and traceability to ensure food safety. A few methods of DNA isolation from milk have been reported, but many of them are time consuming and expensive. Here, we report a rapid, simple, and efficient method of mtDNA extraction from raw and processed milk (pasteurized, retorted, and UHT milk) to generate substrate for analysis using any PCR analysis platform. Various techniques used for the separation of mitochondria were explored and combined with a sodium dodecyl sulfate method for mtDNA extraction from raw and processed milk. The optimized protocol supports the efficient amplification of mtDNA independent of sample origin and is sufficiently straightforward to allow its widespread adoption by industry.
\end{abstract}

Key words: milk, mitochondrial (mt)DNA, PCR amplification, species identification

\section{INTRODUCTION}

Food quality and safety are increasing concerns for industry supply chains as the dairy industry seeks to meet increasingly stringent regulatory requirements and the need for consumer acceptance. In particular, analysis of milk and milk products is now mandatory, given the exposure of newborns and the consequential pressure to demonstrate authenticity to the consumer (Pirondini et al., 2010). Although dairy products sold for public consumption must be accurately labeled as to what milk species they are derived from (López-Calleja et al., 2007a), the inappropriate substitution of ewe and goat milks by cow milk is still frequently reported, given that the production of cow milk is prevalent in many countries and cow milk is cheaper than other

Received January 26, 2017.

Accepted May 12, 2017.

${ }^{1}$ Corresponding author: yongfeng200@126.com types of milk (Borkova and Snaselova, 2005). To ensure accurate monitoring, an effective method that can discriminate between species is needed. Although a variety of technological methods, including immunological, electrophoretic, and chromatographic approaches, have been applied to the identification of adulteration of milk and dairy products (Enne et al., 2005; Mayer, 2005; López-Calleja et al., 2007b), the most common way to identify differences in dairy products is based on PCR, given its low limits of detection, strong specificity, and high sensitivity.

Authentication by PCR is generally based on mitochondrial (mt)DNA rather than nuclear (n)DNA, as mtDNA represents the maternal biological contribution and offers the screening advantage of greater sequence diversity than nDNA (Vawter and Brown, 1986; Brown et al., 1993). An additional technical advantage for amplifying target sequences from mtDNA is the high copy number per cell (Robin and Wong, 1988). Thus, PCR is more likely to amplify a fragment within the mitochondrial genome rather than within the nuclear genome, especially in processed samples that may have suffered DNA degradation. Isolation of high-quality mtDNA is therefore a critical initial step for species-oforigin identification based on PCR analysis.

The application of molecular methods to milk samples requires stringent extraction and purification strategies to ensure efficient recovery of nucleic acid and efficient removal of numerous compounds that might inhibit the PCR assay. Milk is a ready source of DNA (Lipkin et al., 1993), and numerous methods have been developed as research protocols (d'Angelo et al., 2007; Liu et al., 2014; Pokorska et al., 2016) and extended to commercial kits. However, these protocols are generally time consuming and are usually focused on genotyping rather than species identification in dairy products. Although commercial kits offer the advantage of being quicker to carry out, they remain expensive (Pirondini et al., 2010). Therefore, the primary objective of the current study was to develop a very fast, simple, and cheap method for isolation of mtDNA in particular that could be readily applied to both raw and processed milk. The 
proposed protocol is not only effective and reliable in generating mtDNA but is well suited to providing suitable mtDNA for direct PCR amplification.

\section{MATERIALS AND METHODS}

\section{Sample Collection}

Samples of raw milk were collected from a local farm producer and transported on ice packs (to maintain an optimum low temperature) to the laboratory. The processed milk samples, including pasteurized, retorted, and UHT milk, were collected from the local market. To test the applicability of the method proposed here, 12 raw milk samples were prepared from 3 cows, and 12 processed milk samples for each type of milk product were prepared from 3 separate milk products for mtDNA extraction. To test the reproducibility of the method proposed here, these samples were prepared on different days (d 1 and d 2 samples) for mtDNA extraction.

\section{Mitochondrial DNA Extraction}

Milk samples $(10 \mathrm{~mL})$ were centrifuged at 5,000 $\times$ $g$ for $10 \mathrm{~min}$ at room temperature, removing the milk fat and most of the supernatant. The sediment was washed with $600 \mu \mathrm{L}$ of PBS and transferred to a $1.5-\mathrm{mL}$ centrifuge tube and re-centrifuged at 5,000 $\times g$ for 10 min at room temperature. Then, the supernatant was discarded and $500 \mu \mathrm{L}$ of chilled homogenizing buffer (0.25 $M$ sucrose, $10 \mathrm{~m} M$ EDTA, and $30 \mathrm{~m} M$ Tris-HC1, $\mathrm{pH} 7.5$ ) was added to the $1.5-\mathrm{mL}$ centrifuge tube for homogenization (a micro-pellet pestle was used to ensure that most of the cells were broken). After homogenate, the mixture was centrifuged at 1,200 $\times g$ for 5 min at room temperature to precipitate the nuclei and cellular debris; then, the supernatant was recovered and centrifuged at $12,000 \times g$ for $10 \mathrm{~min}$ at room temperature to precipitate the mitochondrial sediment.

The mitochondrial sediment was incubated at $65^{\circ} \mathrm{C}$ for $15 \mathrm{~min}$ with $10 \mu \mathrm{L}$ of proteinase $\mathrm{K}(20 \mathrm{mg} / \mathrm{mL}), 50$ $\mu \mathrm{L}$ of SDS $(200 \mathrm{mg} / \mathrm{mL})$ and $200 \mu \mathrm{L}$ of mtDNA extraction buffer $(0.1 \mathrm{M} \mathrm{NaCl}, 50 \mathrm{~m} M$ Tris- $\mathrm{HCl}$ and $5 \mathrm{mM}$ EDTA, pH 8.0). Then, $500 \mu \mathrm{L}$ of absolute ethanol was added to the $1.5-\mathrm{mL}$ centrifuge tube and centrifuged at $10,000 \times g$ for $3 \mathrm{~min}$ at room temperature to precipitate the mtDNA. Finally, the top ethanol layer was carefully removed and dried in the air, and Tris-EDTA $(50 \mathrm{mM}$ Tris- $\mathrm{Cl}$ and $5 \mathrm{~m} M$ EDTA, $\mathrm{pH}=8.0$ ) was added to dissolve the mtDNA. The yield was calculated using a UV/VIS spectrophotometer (Thermo Fisher Scientific
Inc., Waltham, MA) and the absorption ratio at 260 and $280 \mathrm{~nm}$ (A260/A280) was taken as a purity index.

\section{PCR Detection}

The 12S rRNA gene was selected as a target sequence for the specific detection of mtDNA. The sequences were as follows: 5'-CTAGAGGAGCCTGTTCTATAATCGATAA-3' and 5'-AAATAGGGTTAGATGCACTGAATCCAT-3' (López-Calleja et al., 2005). The PCR was performed on C1000 Thermal Cycler (BioRad, Hercules, CA) in 10- $\mu \mathrm{L}$ volumes containing $3.4 \mu \mathrm{L}$ of $2 \times$ TaqMan Universal PCR Master Mix (CWBIO, Beijing, China), assay-specific primers at $0.3 \mu M, 1 \mu \mathrm{L}$ of the normalized template (100 ng), with the volume made up to $10 \mu \mathrm{L}$ with DNase-/DNA-free water (CWBIO). The PCR protocol was $95^{\circ} \mathrm{C}$ for $10 \mathrm{~min}$ followed by 30 cycles at $94^{\circ} \mathrm{C}$ for $30 \mathrm{~s}, 60^{\circ} \mathrm{C}$ annealing for $30 \mathrm{~s}$, $72^{\circ} \mathrm{C}$ for $30 \mathrm{~s}$, and a final extension at $72^{\circ} \mathrm{C}$ for $10 \mathrm{~min}$. To visualize the PCR products for purity and quality, agarose gel electrophoresis was applied. Each sample was loaded onto $1.0 \%$ (wt/vol) agarose gel. The electrophoresis was carried out in $1 \times$ Tris-acetate-EDTA buffer (40 $\mathrm{m} M$ Tris acetate, $1 \mathrm{~m} M$ EDTA) at $100 \mathrm{~V}$ for $40 \mathrm{~min}$. The gels were visualized by staining with DuRed (CWBIO) and photographed under UV light.

\section{Real-Time PCR Detection}

Ten-fold serially diluted mtDNA extracts (ranging from 100 to $0.01 \mathrm{ng}$ ) from raw, pasteurized, retorted, and UHT milk were analyzed to determine the sensitivity of the assay based on primer pair $12 S$ rRNA as described above. The standard curves were obtained by plotting the cycle threshold $(\mathbf{C t})$ values of realtime PCR analysis against the logarithm of the initial mtDNA amount. Real-time PCR was performed under standard 3-step thermal cycling conditions: $95^{\circ} \mathrm{C}$ for 10 min followed by 40 cycles of $94^{\circ} \mathrm{C}$ for $30 \mathrm{~s}, 60^{\circ} \mathrm{C}$ annealing for $60 \mathrm{~s}$, and $72^{\circ} \mathrm{C}$ extension for $60 \mathrm{~s}$ using a PIKO REAL 96 real-time PCR System (Thermo Fisher Scientific Inc.). Reactions were carried out with $5 \mu \mathrm{L}$ of Power SYBR Green Master Mix (CWBIO), $0.4 \mathrm{mM}$ assay-specific primers, $1 \mu \mathrm{L}$ of normalized template (corresponding to absolute mtDNA amounts of 100, 10, $1,0.1$, and $0.01 \mathrm{ng}$, respectively), and made up to $10 \mu \mathrm{L}$ with DNase-/DNA-free water (CWBIO).

\section{Economic Evaluation}

Evaluations of some published DNA extraction methods were compared with our method according to 
the time and costs required for each method and the difficulty of its performance.

\section{RESULTS AND DISCUSSION}

\section{Mitochondrial DNA Yield and Purity}

Determination of double-stranded DNA concentration and purity is important for downstream applications such as PCR and multiplex PCR. In the present study, we evaluated the yield and purity of mtDNA extracted from 4 types of milk samples. Yields of mtDNA extracted from raw, pasteurized, retorted, and UHT milk ranged from 0.18 to $0.33 \mu \mathrm{g}, 0.20$ to $0.27 \mu \mathrm{g}, 0.19$ to $0.29 \mu \mathrm{g}$, and 0.27 to $0.37 \mu \mathrm{g}$, respectively. The corresponding purity values ranged from 1.13 to $1.27,1.10$ to $1.24,1.15$ to 1.25 , and 1.17 to 1.30 (Table 1 ). The mtDNA yields were acceptable for PCR analysis but the range of mtDNA yields was large (from 0.18 to 0.37 $\mu \mathrm{g})$. The difference in yields might be correlated with the complexity of the milk composition and the presence of molecules such as free nucleotides, protein, and RNA, which could interfere in the reading of absorbance at $260 \mathrm{~nm}$. In the differential centrifugation method used here, nuclei and cell debris are first pelleted by lowspeed centrifugation, and mitochondria and other small molecules are later pelleted by high-speed centrifugation. Despite this, some residual low-molecular-weight nucleotides remained with the mitochondrial fraction. The purity ratios we obtained from all milk sample types were lower than 1.80 (ranging from 1.10 to 1.30), which was not expected for pure samples (Murray and Thompson, 1980), but it was still possible to generate satisfactory amounts of template for PCR analysis.

\section{PCR Detection}

DNA barcoding has been successfully used to authenticate different dairy products and detect fraudulent substitution. It requires the recovery of species-specific DNA fragments, but the level of DNA recovery and subsequent accuracy of analysis from heat-processed milk may suffer from both degradation and presence of various inhibitors of the PCR process. To evaluate the influence of heat treatment on the specific method developed herein, mtDNA was extracted from both unprocessed (raw) and several processed milks, and the extracted mtDNA in each case was assessed by PCR amplification. As shown in Figure 1, the PCR amplification of the 12S rRNA region from raw and processed milk samples produced a single sharp band of the expected molecular size, indicating that the crude mtDNA obtained using our protocol was indeed substantial and sufficiently purified that DNA polymerase activity was not inhibited. DNA is known to be a heat-sensitive molecule, and commercially sterilized milk is often produced by a heating process that ensures safety from microbiological contamination and thus extends shelf life. In particular, retorted milk is produced by heating raw milk at high temperature (from 110 to $120^{\circ} \mathrm{C}$ ) for several minutes; and UHT milk is produced by heating raw milk at even higher temperatures (about from 135 to $145^{\circ} \mathrm{C}$ ) but for only a few seconds. In both cases, this heat treatment would be expected to cause some degree of double-stranded DNA denaturation that may severely impair PCR amplification. Surprisingly, the PCR bands from both the retorted and UHT milk samples were comparable to those observed with raw fresh milk, suggesting our protocol could be generally applicable to dairy samples at all levels of industrial processing. In addition, to evaluate the reproducibility of our analysis approach, milk samples were prepared on different days (d 1 and d 2 samples), and as shown in Figure 1, the specific mtDNA fragments in each case were indistinguishable, suggesting that our method was repeatable.

\section{Real-Time PCR Detection}

Real-time PCR is now commonly used for quantification of specific DNA fragments. To further evaluate any negative effects of industrial heat treatments on the detectability of mtDNA, the sensitivity of selected primer was determined by analysis of serially diluted

Table 1. Yield and purity (absorbance at 260/280 nm) of mitochondrial DNA isolated from 4 types of milk ${ }^{1}$

\begin{tabular}{lccccc}
\hline & \multicolumn{2}{c}{ Yield $(\mu \mathrm{g})$} & & \multicolumn{2}{c}{ Purity $(\mathrm{A} 260 / \mathrm{A} 280)$} \\
\cline { 2 - 3 } \cline { 5 - 6 } Milk type & \multirow{2}{*}{ Minimum } & Maximum & & Minimum & Maximum \\
\hline Raw milk & 0.18 & 0.33 & & 1.13 & 1.27 \\
Pasteurized milk & 0.20 & 0.27 & & 1.10 & 1.24 \\
Retorted milk & 0.19 & 0.29 & & 1.15 & 1.25 \\
UHT milk & 0.27 & 0.37 & & 1.17 & 1.30 \\
\hline
\end{tabular}

${ }^{1}$ Results were obtained from $10-\mathrm{mL}$ milk samples. 


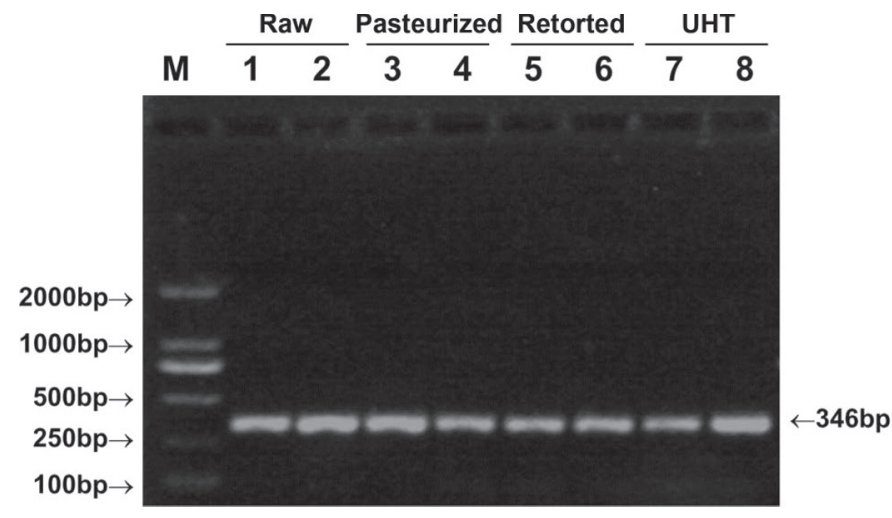

Figure 1. Representative PCR results from raw and processed milks. $\mathrm{M}=$ molecular weight marker (2,000-bp DNA ladder); lanes 1 and 2: raw milk (d 1 and d 2 samples, respectively); lanes 3 and 4: pasteurized milk (d 1 and d 2 samples, respectively); lanes 5 and 6 : retorted milk (d 1 and d 2 samples, respectively); lanes 7 and 8: UHT milk (d 1 and d 2 samples, respectively).

mtDNA extracts from raw, pasteurized, retorted, and UHT milk used in real-time PCR with SYBR Green dye. Plotting the $\mathrm{Ct}$ values obtained in the analysis of serially diluted mtDNA extracts against the logarithm of the initial mtDNA amount resulted in 4 separate linear standard curves in the range from 100 to $0.01 \mathrm{ng}$ of mtDNA (Figure 2). The $\mathrm{R}^{2}$ values of the standard curves obtained from raw, pasteurized, retorted, and UHT milk were $0.9900,0.9853,0.9853$, and 0.9774 , re- spectively, and considered acceptable $\left(\mathrm{R}^{2}>0.95\right)$ in all cases. For all milk samples, the limit of detection was $0.01 \mathrm{ng}$ of bovine mtDNA. These results confirm that our protocol is widely applicable to most sources of the commercially sterilized milk, and the extracted mtDNA from both raw and processed milk is appropriate for quantification analysis.

\section{Economic Evaluation}

In identifying a useful, reliable protocol suitable for extracting DNA from different dairy products, several parameters should be considered as evaluation criteria: (a) time and (b) cost required for the entire procedure; and (c) the efficiency of the different methods (Pirondini et al., 2010). The rapid and efficient mtDNA preparation method that we developed for both milk and milk products is not only compatible with the most widely used analysis platforms (PCR and real-time PCR), but it will generate the necessary mtDNA substrate within an hour, comparable to most of the commercial kits and faster than most research protocols (Table 2). In addition, our protocol is cost effective and requires readily available technical skill sets.

In general, mtDNA extraction methods usually rely on DNase I or RNase to remove nDNA or RNA (Palva and Palva, 1985; Tamura and Aotsuka, 1988), but this procedure was not included in the current study. The focus of the present study was not to obtain purified

\section{$\bullet$ Raw milk $\quad$ Pasteurized milk $\Delta$ Retorted milk $\quad \times$ UHT milk}

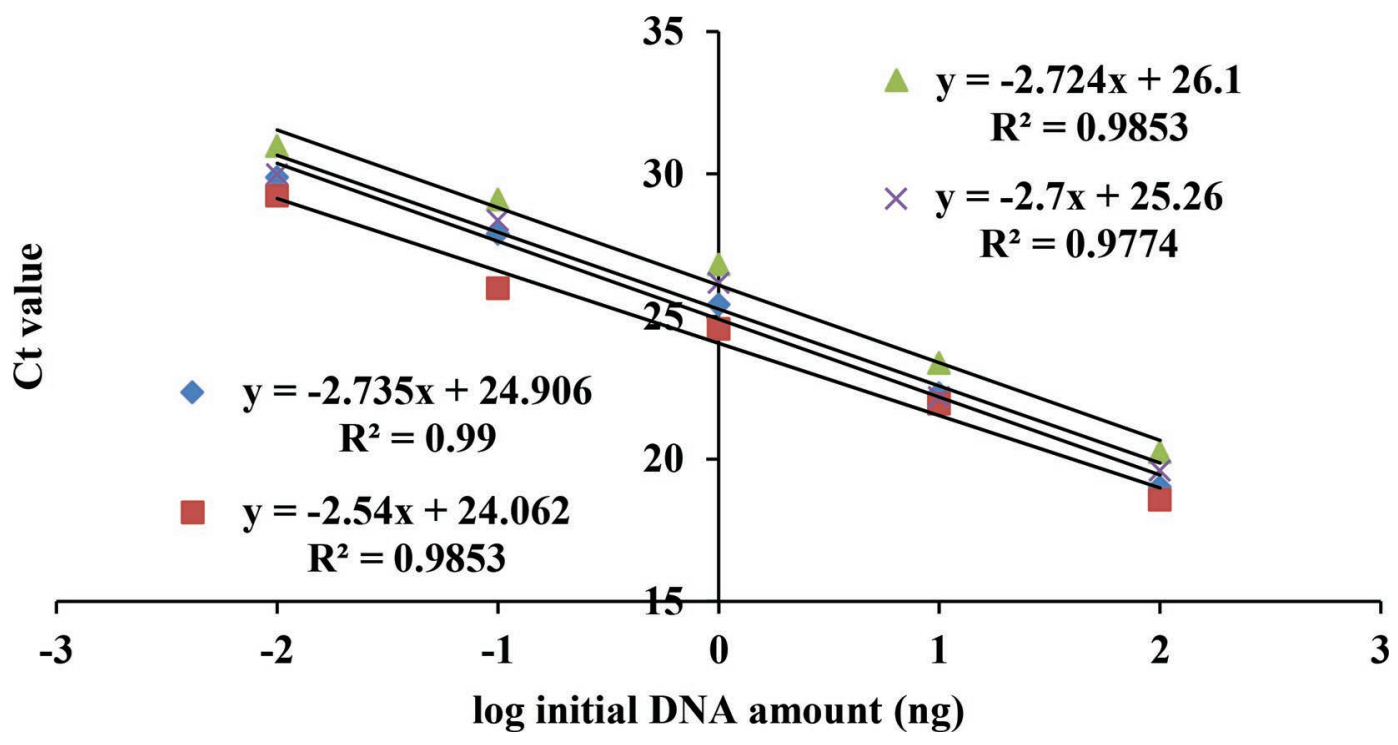

Figure 2. Standard curves obtained by analyzing serially diluted mitochondrial DNA extracts from different milk samples. Results are mean of cycle threshold $(\mathrm{Ct})$ value $(\mathrm{n}=3)$. Color version available online. 
Table 2. Estimation of the labor intensity, time, and material costs for DNA extraction using different extraction methods

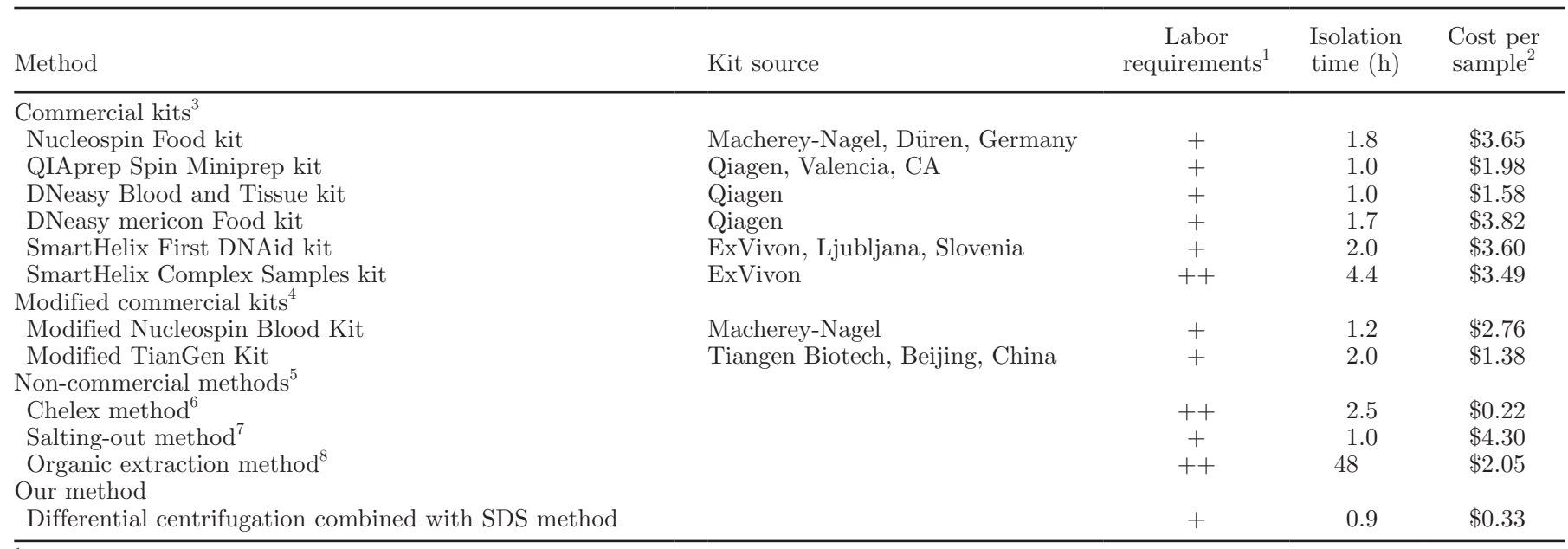

${ }^{1}$ Where $+=$ very easy; $++=$ easy.

${ }^{2}$ The cost per sample has been converted from euro to dollar; the euro to dollar conversion factor is 1:1.1.

${ }^{3}$ Data from Volk et al. (2014).

${ }^{4}$ Data from Usman et al. (2014).

${ }^{5}$ Data from Pokorska et al. (2016).

${ }^{6}$ Method from Amills et al. (1997).

${ }^{7}$ Method from d'Angelo et al. (2007).

${ }^{8}$ Method from Liu et al. (2014).

mtDNA without any nDNA or RNA but rather to characterize the methodology of PCR-based detection of mtDNA; therefore, it was not necessary to obtain a purified mtDNA fraction without nDNA or RNA.

\section{CONCLUSIONS}

The new procedure presented here was fast, cheap, simple, and reliable, providing an efficient protocol for rapid isolation of mtDNA from raw and processed milk. The extracted mtDNA was suitable for both standard PCR and real-time PCR analysis. Thus, this improved protocol is a meaningful advance with an enlarged scope of applicability for future food traceability and dairy product identification.

\section{ACKNOWLEDGMENTS}

This work was supported by the China postdoctoral science foundation (2015M570811), the national twelfth "Five Year" science and technology support project (2012BAD12B07), the fundamental research funds for the central universities of China (GK201502008) and the college students' innovative entrepreneurial training plan of Shaanxi Normal University (CX16034; Xi'an, China).

\section{REFERENCES}

Amills, M., O. Francino, M. Jansa, and A. Sanchez. 1997. Isolation of genomic DNA from milk samples by using Chelex resin. J. Dairy Res. 64:231-238.

Borkova, M., and J. Snaselova. 2005. Possibilities of different animal milk detection in milk and dairy products - A review. Czech J. Food Sci. 23:41-50.

Brown, J. R., A. T. Beckenbach, and M. J. Smith. 1993. Intraspecific DNA sequence variation of the mitochondrial control region of white sturgeon (Acipenser transmontanus). Mol. Biol. Evol. $10: 326-341$.

d'Angelo, F., A. Santillo, A. Sevi, and M. Albenzio. 2007. Technical note: A simple salting-out method for DNA extraction from milk somatic cells: Investigation into the goat CSN1S1 gene. J. Dairy Sci. 90:3550-3552.

Enne, G., D. Elez, F. Fondrini, I. Bonizzi, M. Feligini, and R. Aleandri. 2005. High-performance liquid chromatography of governing liquid to detect illegal bovine milk's addition in water buffalo Mozzarella: comparison with results from raw milk and cheese matrix. J. Chromatogr. A 1094:169-174.

Lipkin, E., A. Shalom, H. Khatib, M. Soller, and A. Friedmann. 1993. Milk as a source of deoxyribonucleic acid and as a substrate for the polymerase chain reaction. J. Dairy Sci. 76:2025-2032.

Liu, Y. F., J. L. Gao, Y. F. Yang, T. Ku, and L. S. Zan. 2014. Novel extraction method of genomic DNA suitable for long-fragment amplification from small amounts of milk. J. Dairy Sci. 97:6804-6809.

López-Calleja, I., I. G. Alonso, V. Fajardo, M. A. Rodríguez, P. E. Hernández, T. García, and R. Martín. 2005. PCR detection of cows' milk in water buffalo milk and mozzarella cheese. Int. Dairy J. 15:1122-1129.

López-Calleja, I., I. González, V. Fajardo, I. Martín, P. E. Hernández, T. García, and R. Martín. 2007a. Real-time TaqMan PCR for quantitative detection of cows' milk in ewes' milk mixtures. Int. Dairy J. 17:729-736. 
Lopez-Calleja, I. M., I. Gonzalez, V. Fajardo, P. E. Hernandez, T. García, and R. Martín. 2007b. Application of an indirect ELISA and a PCR technique for detection of cows' milk in sheep's and goats' milk cheeses. Int. Dairy J. 17:87-93.

Mayer, H. K. 2005. Milk species identification in cheese varieties using electrophoretic, chromatographic and PCR techniques. Int. Dairy J. 15:595-604.

Murray, M. G., and W. F. Thompson. 1980. Rapid isolation of high molecular weight plant DNA. Nucleic Acids Res. 8:4321-4325.

Palva, T. K., and E. T. Palva. 1985. Rapid isolation of animal mitochondrial DNA by alkaline extraction. FEBS Lett. 192:267-270.

Pirondini, A., E. Maestri, G. Visioli, M. Marmiroli, and N. Marmiroli. 2010. Yield and amplificability of different DNA extraction procedures for traceability in the dairy food chain. Food Contr. 21:663-668.

Pokorska, J., D. Kułaj, M. Dusza, J. Żychlińska-Buczek, and J. Makulska. 2016. New rapid method of DNA isolation from milk somatic cells. Anim. Biotechnol. 27:113-117.
Robin, E. D., and R. Wong. 1988. Mitochondrial DNA molecules and virtual number of mitochondria per cell in mammalian cells. J. Cell. Physiol. 136:507-513.

Tamura, K., and T. Aotsuka. 1988. Rapid isolation method of animal mitochondrial DNA by the alkaline lysis procedure. Biochem. Genet. 26:815-819.

Usman, T., Y. Yu, C. Liu, Z. Fan, and Y. Wang. 2014. Comparison of methods for high quantity and quality genomic DNA extraction from raw cow milk. Genet. Mol. Res. 13:3319-3328.

Vawter, L., and W. M. Brown. 1986. Nuclear and mitochondrial DNA comparisons reveal extreme rate variation in the molecular clock. Science 234:194-196.

Volk, H., S. Piskernik, M. Kurinčič, A. Klančnik, N. Toplak, and B. Jeršek. 2014. Evaluation of different methods for DNA extraction from milk. J. Food Nutr. Res. 53:97-104. 